\title{
Virgin olive oil reduces blood pressure in hypertensive elderly subjects
}

Javier S. Perona*, Julio Cañizares ${ }^{\dagger}$, Emilio Montero $^{\ddagger}$, José M. SánchezDomínguez $^{*}$, Angel Catalá ${ }^{\S}$ and Valentina Ruiz-Gutiérrez ${ }^{* 1}$

\footnotetext{
*Instituto de la Grasa, Consejo Superior de Investigaciones Científicas, 41012 Sevilla, Spain.

${ }^{\dagger}$ Residencia Heliópolis de la Tercera Edad, Junta de Andalucía, 41012 Sevilla, Spain. ${ }^{\ddagger}$ Hospitales Universitarios Virgen del Rocío, 41013 Sevilla, Spain.

${ }^{\S}$ Cátedra de Bioquímica, Facultad de Ciencias Veterinarias, Universidad Nacional de La Plata, La Plata, Argentina.
}

${ }^{1}$ Corresponding author. Instituto de la Grasa. Av. Padre García Tejero, 4. 41012 Sevilla, Spain. Phone: 34-954611550. Fax: 34-954616790. E-mail:valruiz@cica.es Short title: Virgin olive oil and blood pressure in elderly 


\section{Abstract}

Background and aims: Hypertension is one of the most important risk factors for coronary heart disease. Recent studies have pointed out the possibility that virgin olive oil may lower blood pressure in hypertensive subjects. However, until the date there is scarce information regarding elderly people. The present study was designed to assess the effect of dietary virgin olive oil on blood pressure in medically-treated hypertensive elderly patients.

Methods: 31 medically-treated hypertensive (HT) elderly patients and 31 normotensive (NT) elderly volunteers participated in a randomized sequential dietary intervention. Subjects consumed diets enriched in sunflower oil (SO) or virgin olive oil (VOO) for four weeks each with a four-week washout period between them.

Results: VOO reduced total and LDL-cholesterol in NT but not in HT $(p<0.01)$ and the concentrations were lower than in the group consuming SO. In contrast, no significant differences were found in the levels of tocopherols among the groups studied. Ironinduced oxidation of LDL resulted in a complete loss of monoacylglycerols (MG) and diacylglycerols (DG) and a reduction in triacylglycerols (TG) (60-80\%), which was found to be greater in HT $(p<0.01)$ with no effect of diet. VOO consumption normalized systolic pressure in the HT group (136 $\pm 10 \mathrm{mmHg}$ ) compared to SO (150 $\pm 8 \mathrm{mmHg}$ ). Conclusion: dietary VOO proved to be helpful in reducing the systolic pressure of treated HT elderly subjects. However, a greater resistance to the lowering effect of VOO of total and LDL-cholesterol and a greater susceptibility to TG oxidation was detected in these patients.

Key-words: virgin olive oil, elderly, hypertension, cholesterol, tocopherol 


\section{Introduction}

In elderly people, both isolated systolic hypertension and combined systolic/diastolic hypertension are considered the most important risk factors for coronary heart disease morbidity and mortality (1). In fact, hypertension affects more than one half of the elderly and its prevalence increases with age (2). When hypertension is treated, the cardiovascular morbidity and mortality is reduced to a greater extent than could be expected from the results of trials in middle-aged subjects (3). However, nutritional supplementation has acquired an important relevance, partially because many antihypertensive agents elevate low-densitylipoprotein-cholesterol (LDL) or triacylglycerol (TG) concentrations and/or lower highdensity-lipoprotein-cholesterol (HDL) concentrations, paradoxically increasing the cardiovascular risk $(4,5)$.

Despite fish oil or n-3 fatty acid supplementations have been employed as adjuvants in the treatment of hypertension, several studies did not find a reduction in blood pressure of hypertensive (HT) patients, when compared with virgin olive oil (VOO) supplementation $(6,7)$. We demonstrated that the intake of VOO lowers both systolic and diastolic pressures in normocholesterolemic and hypercholesterolemic hypertensive women when compared with a diet enriched in high-oleic sunflower oil (HOSO) (8). In addition, VOO, but not HOSO, also normalized some of the impaired functions of the erythrocyte membrane in HT (9). Subsequently, other authors have corroborated our findings $(10,11)$.

The concentration of antioxidants in VOO has also been related to a resistance of LDL to oxidation $(12,13)$. Oxidative modification of LDL has been implicated as an important determinant in the development of atherosclerosis (14). Susceptibility of plasma LDL to oxidation from different subjects ex vivo is highly variable and is related, among other factors, to the TG, polyunsaturated fatty acids (PUFA) and vitamin E contents (15). In fact, LDL oxidation is increased by adding PUFA to the diet, such as SO, and decreased by adding vitamin E. De Waart et al., (16) reported that supplementation with vitamin $\mathrm{E}$ in the elderly is beneficial for lowering the rate of oxidation of linoleic acid in the LDL of elderly people, whose LDL are more susceptible to oxidation (17). LDL are also more prone to be oxidized in patients affected by hypertension (18) but it that can be prevented adding vitamin $E$ to the 
diet since it reduces the susceptibility to oxidative modification of LDL by means of increasing oxidation lag time (19).

The present work was conducted with the aim of evaluating the effects of dietary VOO and SO on blood pressure and on the lipid composition of LDL and oxidized LDL (oxLDL) in a group of non-diabetic medically-treated HT elderly people (average age 84y). In addition, we evaluated the concentration of $\alpha$-tocopherol and other vitamins and non-fatty acid constituents of dietary VOO that might be related to the susceptibility of LDL to oxidation. 


\section{Subjects and Methods}

The study was performed at Residencia Heliópolis (Junta de Andalucía, Seville, Spain), a residential home for the elderly, where the diet of all participants was controlled. 42 women and 20 men ( 31 NT and 31 HT), who were residents at the beginning of the study, gave written, informed consent to a protocol approved by the Institutional Committee on Investigation in Humans (Hospitales Universitarios Virgen del Rocío, Seville, Spain). All participants had been residents of the Residencia Heliópolis for at least 5 years, consequently all their habits were completely known. $\mathrm{HT}$ volunteers had been suffering from hypertension for at least the last 5 years and were medically-treated with beta-blockers and diuretics. None of them was diabetic or suffered from glucose intolerance or hypothyroidism. Fasting glucose levels were $101.1 \pm 28.1 \mathrm{mg} / \mathrm{dL}$ for normotensives and for hypertensives $95.1 \pm 12.6 \mathrm{mg} / \mathrm{dL}$. Cigarette smokers were excluded from the study and no case of alcohol abuse was detected among participants.

\section{Diets}

The participants were successively fed two diets enriched in SO or VOO for four weeks each. A 4-week washout period was included between experimental periods, consisting on the habitual dietary fat, comprised of refined oil and a blend of seed oils. Before the study, the health officers recorded the habitual dietary intake of the participants during four consecutive weeks, using a $24 \mathrm{~h}$ recall and food frequency questionnaires. The energy consumption and nutrient intake were calculated, approved by a dietician and employed as a basis for the diets of the study. The studied diets were based on ordinary food and were planned for every four-week period and were revised every week. The diet was adjusted to $30 \%$ of the energy as fat, $55 \%$ as carbohydrates and $15 \%$ as proteins. Oils were added to the diet in a daily dose of $60 \mathrm{~g}$. The fatty acid composition of the oils was performed by gas chromatography as described below and is shown in Table 1. Three diet samples were collected in each experimental period to be analyzed for their fat content and other nutrients. One investigator was present several times in the kitchen during meal preparation without previous notification. The energy consumption was approximately $1800 \mathrm{kcal} / \mathrm{day}$. Sodium intake was identical in both experimental periods. 


\section{Blood Pressure Measurements}

Blood pressure measurements were performed in the morning, after an overnight fast, at the right brachial artery in seated participants using a mercurygauge sphyngomanometer. The measurements were recorded by the same nurse at the residential home at the beginning, middle and end of every experimental period. At each visit three blood pressure measurements were recorded and the average used to determine eligibility.

\section{Serum lipid and lipoprotein analyses}

Venous blood was obtained in fasting status after an overnight period, at the beginning and end of each period of the study. Blood was collected in Vacutainer ${ }^{\circledR}$ tubes and serum obtained by centrifugation at $1500 \mathrm{rpm}$ during $30 \mathrm{~min}$ at $4{ }^{\circ} \mathrm{C}$. Serum samples were frozen below $-80 \stackrel{\circ}{\circ}$ until analyzed. Serum total and high-densitylipoprotein (HDL) cholesterol and TG concentrations were measured by conventional enzymatic methods. Low-density-lipoprotein (LDL) cholesterol concentration was calculated according to the Friedewald equation.

\section{Isolation and Oxidation of Low-Density Lipoproteins (LDL)}

LDL were isolated by density gradient ultracentrifugation from $4 \mathrm{~mL}$ of serum (40000 rpm, 18 h, $15 \stackrel{\circ}{\circ}$ ). Ultracentrifugation was performed using a SW 41 Ti rotor in a BECKMAN L8-70M preparative ultracentrifuge (Beckman Instruments, Inc, Palo Alto, USA). Lipid peroxidation was assayed by incubating LDL ( $1 \mathrm{mg}$ of protein) in $0.05 \mathrm{M}$ phosphate buffer, $\mathrm{pH} 7.4$ at $37^{\circ} \mathrm{C}$, final volume $2 \mathrm{~mL}$. The reaction was started by addition of ascorbate (final concentration $0.4 \mathrm{mM}$ ). Phosphate buffer was contaminated with sufficient iron to provide the necessary ferrous or ferric iron for lipid peroxidation.

\section{Determination of Serum Vitamins and Squalene}

Squalene was determined by gas chromatography after extraction from total lipids using the method described by Lanzon et al. (20). Liposoluble vitamins were extracted from $500 \mu \mathrm{L}$ of serum as follows. $500 \mu \mathrm{L}$ of ethanol and $1 \mathrm{~mL}$ of hexane were added sequentially. The mixture was centrifuged ( $3500 \mathrm{rpm}, 15^{\circ} \mathrm{C}$ for $10 \mathrm{~min}$ ) 
and the supernatant collected. The hexane was evaporated under a stream of nitrogen and the vitamins redissolved in choloroform/methanol $(2: 1, v / v)$ for injection into the HPLC system. This system consisted on a reversed-phase column (Novapack, $4 \times 250 \mathrm{~mm}, 4 \mu \mathrm{m})$ and an elution system composed of methanol/acetonitrile (chloroform (9:78:13, v/v/v) that run isocratically. A photodiode array detector (PAD 996, Waters) was used for $\alpha$-tocopherol, $\gamma$-tocopherol and retinol detection at $290 \mathrm{~nm}$ ( $\alpha$-tocopherol and $\gamma$-tocopherol) and $325 \mathrm{~nm}$ (retinol), respectively. These compounds were identified by using commercial standards and quantified by means of external standard.

\section{Determination of LDL and oxLDL Lipid Classes}

Total lipids were extracted following a modification of the method of Rose and Oaklander (21), using 2,6-di-tert-butyl-p-cresol (BHT) as antioxidant. $10 \mu \mathrm{L}$ of lipids from LDL and oxLDL were dissolved in chloroform/methanol $(2: 1, v / v)$ and were injected in a 2690 Alliance liquid chromatograph (Waters, Milford, USA), controlled by computer (Millenium 34 System, Waters, Milford, USA) and provided with a Lichrosphere column (250 x $4.6 \mathrm{~mm}, 5-\mu \mathrm{m}$ particle size) (Merck, Darmstadt, Germany). The liquid chromatograph was coupled to a light-scattering detector (DDL31 Eurosep Ins., CergyPontoise, France). The mobile phase consisted on a ternary solvent system, starting with $0.8 \%$ of 2-propanol in hexane raising the percentage of 2-propanol to $3.0 \%$ in $8 \mathrm{~min}$ and then to $10.0 \%$ after $17 \mathrm{~min}$. From minute 17 to minute 22 , the percentages of hexane and 2-propanol were reduced to $0 \%$, whereas that of methanol was raised to $100 \%$. The flow rate was $0.8 \mathrm{~mL} / \mathrm{min}$. Standard solutions of cholesterol oleate, triolein, 1,2-diolein, 2monoolein, cholesterol and dipalmitoyl phosphatidylethanolamine (Sigma, St. Louis, USA) were used for identification and quantification. For calibration, triplicate runs of six concentrations of these standards $(0.25$ and $2.5 \mathrm{mg} / \mathrm{mL}$ in chloroform/methanol, $2: 1)$ were injected. Equations resulting from regression curves of these standards were employed for quantification.

\section{Statistical Analyses}

Values are shown as mean \pm standard deviation. The significance of the difference among groups was assessed by analysis of variance (ANOVA) with Tukey's post-hoc comparison of the means. Differences were considered significant with a 
confidence interval of $99 \%(p<0.01)$. The analyses were done with Prism v3.0 (GraphPAD Software, San Diego, USA).

\section{Results}

During the period of the study, we detected no cardiovascular, nor other metabolic or endocrine disease among the individuals recruited. The average age of the participants was $84.0 \pm 7.4 \mathrm{y}$, and presented an average BMI of $28.8 \pm 5.2 \mathrm{~kg} / \mathrm{m}^{2}$ and a whist to hip ratio (WHR) of $0.91 \pm 0.06$. No relationship was found between the ages, BMI and WHR of the individuals. The content of total polyphenols in VOO was $232 \mathrm{ppm}$ and that of squalene was $3709 \mathrm{ppm}$. These compounds were not detected in SO.

The variations recorded in the blood pressure of the elderly people are depicted in Figure 1. Systolic pressure was normalized in HT by dietary VOO but not by SO. NT individuals showed values close to $139 \mathrm{mmHg}$ after the period of SO whereas HT showed values above to $150 \mathrm{mmHg}$. In contrast, when the subjects consumed the VOO diet both NT and HT presented systolic pressure values close to $135 \mathrm{mmHg}$. No significant differences were found for diastolic pressure.

The concentrations of serum lipids and lipoproteins in the group of HT were not significantly modified after consuming VOO compared to SO (Table 2). In contrast, VOO was responsible for a decrease in total and LDL-cholesterol concentrations in NT $(p<0.01)$. However, a concomitant decrease in HDL-cholesterol and an increase in TG were also observed $(p<0.01)$. Hypertension did not affect cholesterol concentrations when patients consumed VOO but when consuming SO NT showed a lower TG concentration in serum than HT $(p<0.01)$.

The concentration of $\gamma$-tocopherol and $\alpha$-tocopherol in serum were not modified by either of the diets or affected by hypertension (Table 3). However, the concentration of retinol was significantly higher in the elderly after consuming VOO $(p<0.01)$. Unexpectedly, we did not find higher squalene amounts in serum of the subjects after consuming VOO than after SO. Indeed, we found the highest concentration of this cholesterol precursor in HT after the administration of SO.

Six lipid classes were identified and quantified in the LDL of the elderly subjects (Table 4), for instance cholesteryl esters, free cholesterol, TG, 
diacylglycerols (DG), monoacylglycerols (MG) and phospholipids. The determination of these lipid classes provided more information about the lowering in cholesterol observed in the LDL of NT (Table 2). Indeed, such reduction was due to a lower cholesteryl esters concentration and not to a decrease in the amount of free cholesterol. The TG concentration in LDL was lower in NT after SO $(p<0.01)$, mirroring total TG concentration in serum. In contrast, after VOO, the concentration of TG and DG was significantly higher in NT $(p<0.01)$. No significant differences were found in the MG and phospholipid concentrations in LDL.

When LDL underwent iron-induced oxidation, a loss of MG, DG and TG was found (Table 5 and Figure 2). DG and MG could not be detected in oxLDL and TG concentration was reduced in about $50-80 \%$. The greatest oxidation of TG occurred in HT $(p<0.01)$ but diet did not affect it. The reduction in the glyceride fraction occurred concomitantly to an increase in the cholesterol species. The proportion of free and esterified cholesterol was increased in LDL after the intake of either of the dietary oils. Although the cholesteryl ester content found in oxLDL was not significantly different among the groups studied, the lowest increase was found in the group of NT after SO $(p<0.01)$. Oxidation did not affect the phospholipid content of LDL. 


\section{Discussion}

Newly available data is pointing out that, in addition to plasma lipids, VOO intake may also reduce blood pressure in HT and healthy subjects $(8,10,11)$. The present work was designed to assess the effects of VOO and SO on serum lipids, the lipid composition of LDL and oxLDL and blood pressure of medically-treated HT elderly people.

Systolic pressure was reduced in HT participants after consuming the diet rich in VOO. Unfortunately, for the moment there is scarce information on the effect of dietary oils on blood pressure in aged people. Margolin et al., (4) performed doubleblind randomized-controlled studies to compare the effects of the administration of $n$ 3 (fish oil) and n-6 fatty acids to HT elderly people on blood pressure, showing a higher reduction of systolic and diastolic pressures in subjects receiving fish oil. However, some studies failed to find effects of fish oil or n-3 fatty acid supplementation on blood pressure in treated HT when compared to VOO as a placebo, suggesting that $\mathrm{VOO}$ is able to reduce blood pressure to a similar extent. Previously, Ruiz-Gutierrez et al. (8) had observed a hipotensive effect of dietary Voo in HT patients compared to another oleic acid-rich oil, such as high-oleic sunflower oil (HOSO). VOO, but not HOSO, normalized the altered distribution of cholesterol and $\mathrm{Na}^{+}-\mathrm{Li}^{+}$countertransport in the erythrocyte membrane. Although it needs to be elucidated which of the minor constituents of VOO is/are responsible of these effect, on the basis of the accumulated data, we suggest that polyphenols may play a key role in this regard, since these compounds are absent in SO, either the wild type or high-oleic. The mechanism of reduction of blood pressure by polyphenols has been related to endothelium-dependent vasorelaxation via enhanced nitric oxide $(10,22)$.

Classical studies have reported similar effects of dietary intake of VOO and SO on serum lipid concentrations of healthy subjects $(23,24)$. However, there is still need of consensus, since recent works have shown increasing total and LDL-cholesterol concentrations after consuming VOO compared to dietary oils rich in n- 6 fatty acids $(25,26)$ and others have reported greater cholesterol reductions of VOO $(27,28)$. These discrepancies may be due to differences in experimental conditions, including the employment of different varieties of olive oil as we have shown lately (29). In the present study we found a lower total and LDL-cholesterol concentrations in the serum of NT elderly individuals after consumption of VOO but not in HT (Table 2), suggesting that these 
patients would be more resistant to modifications by diet on serum lipid and lipoproteins concentrations. We previously reported a lack of lowering effect of VOO on serum cholesterol in a group of HT postmenopausal women compared to HOSO (8). The content of squalene, the main hydrocarbon in VOO, has been considered hypercholesterolemic compared with SO (30). We found negligible differences in the serum concentrations of squalene in NT or HT elderly individuals after both diets studied, excluding any relationship between squalene concentrations and the observed variations in serum cholesterol. Very scarce studies on the influence of VOO on squalene content have been carried out and for the moment none in an elderly population.

To our knowledge this is the first study in which a dietary intervention with VOO has been conducted in such an old population of HT individuals. Aging results in modifications of the risk factors related to cardiovascular disease (31). In the very elderly, both serum TG and LDL-cholesterol are diminished (32), as well as antioxidants, due to enhanced of oxidative stress (33). There are a growing number of studies indicating that antioxidants may be responsible for some of the protective effects of VOO $(34,35)$. The concentrations of $\alpha$ and $\gamma$-tocopherol in serum of elderly people consuming either SO or VOO were not significantly different. In contrast, the concentration of retinol was higher in NT and HT subjects after consumption of VOO. Low concentrations of serum retinol or vitamin A, as well as tocopherols, have been related to the risk of coronary heart disease (36) and hypertension (37), even in elderly subjects (38). However, the supplementation of these vitamins in the diet seems to have no relevant effect on blood pressure at least in HT patients under medical treatment (39), unless a very high dose is administrated (40). Additionally, the role of the supplementation of these compounds on the risk of CHD is controversial since some interventional studies have reported no clear effect (41).

Nevertheless, the antioxidant role of these vitamins on the resistance of LDL to oxidation and thus as determinant of atherosclerosis have been clearly stated in vitro (14). In order to study the susceptibility to oxidation of LDL obtained from elderly people after consumption of VOO or SO, we analyzed the actual loss of the lipids contained in those lipoproteins. Very commonly, oxidation in LDL is tested indirectly by measuring espectrophotometrically the conjugate diene formation or the production of lipid hydroperoxides, such as malonaldehide (MDA) or thiobarbituric acid reactive substances (TBARS) (42). The HPLC determination of lipid classes in LDL 
allows checking the actual modifications of lipids occurring in LDL due to iron-induced oxidation. We observed a loss of glyceridic lipids (TG, DG and MG), resulting in a proportionate increase in free and esterified cholesterol. Both DG and MG completely disappeared from LDL in all groups studied (NT-VO, NT-SO, HT-VO and HT-SO) but the loss of TG was greater in HT, suggesting that hypertension diminishes the protection of LDL against iron-induced oxidation in elderly subjects. This is of particular interest since it has been reported that LDL peroxides and the susceptibility of LDL to oxidation are increased with aging (17). Frostegard et al. (18) have very recently showed that oxLDL are raised in serum of HT men as determined by antibody targeting of oxidation epitopes in LDL. In has been stated that an improvement of LDL resistance to oxidation is achieved by blood pressure reduction (43) and vitamin E supplementation (19). However, as no effect of the diet and no differences in the tocopherol concentrations were found, our results support the data raising doubts about the antioxidant effect of this vitamin.

The average BMI value of the elderly subjects was close to $28 \mathrm{~kg} / \mathrm{m}^{2}$, which is usually taken as an indicator of overweight and might bias the results of the study. Obesity increases in advanced maturity, mainly due to changes in the body composition related to age. Such modification include the reduction in height, at a rate of $1-2 \mathrm{~cm}$ per year and even quicker after 85 years, resulting in an increase of BMI (44). Heiat et al. (45) reviewed data from 444 articles on the association of BMI and all causes of cardiovascular mortality in geriatric populations concluding that up to $27 \mathrm{~kg} / \mathrm{m}^{2} \mathrm{BMI}$ does nor represent a mortality risk in elderly people and suggested that the world health organization guidelines of BMI may be too restricted for this population. Others have even recommended that elderly people with BMI values between 25 and $30 \mathrm{~kg} / \mathrm{m}^{2}$ and over 70 years old should not be encouraged to lose weight, as it does not represent a risk for cardiovascular mortality (46).

We conclude that dietary VOO is helpful in reducing the systolic pressure of treated HT elderly subjects, thus reducing the requirement of antihypertensive medication. However, in these patients we detected a greater resistance to the lowering effect of VOO in total and LDL-cholesterol and a greater susceptibility to TG oxidation compared to NT individuals, which was not related to tocopherol or squalene concentrations in serum. The differential effects of VOO and SO consumption on serum squalene content in elderly subjects should be further investigated. 


\section{Acknowledgements}

We are thankful to the director, nurses and assistance personnel of the Residencia de la Tercera Edad Heliópolis, for their willingness during the period of the study. We are also grateful, to Grupo Hojiblanca, and in particular to Mr. Mantilla, for supplying the oils employed and for the analytical facilities provided. This work was supported by FEDER funds from the European Community (FEDER 1FD97-2288) and Junta de Andalucia (CAO01-002). 


\section{References}

1. Forette B. Hypertension in very old subjects. Clin Exp Hypertens 1999;21:917-25.

2. Basile J. Hypertension in the elderly: a review of the importance of systolic blood pressure elevation. Clin Hypertens (Greenwich) 2002;4:108-12.

3. Orozco-Valero M. Large therapeutic studies in elderly patients with hypertension. J Hum Hypertens 2002;16:S38-S43.

4. Margolin G, Huster G, Glueck CJ, Speirs J, Vandegrift J, Illig E, Wu J, Streicher P, Tracy T.. Blood pressure lowering in elderly subjects: a double-blind crossover study of $\omega-3$ and $\omega-6$ fatty acids. Am J Clin Nutr 1991;53:562-72.

5. Brook RD. Mechanism of differential effects of antihypertensive agents on serum lipids. Curr Hypertens Rep 2000;2:370-7.

6. Wing LM, Nestel PJ, Chalmers JP, Rouse I, West MJ, Bune AJ, Tonkin AL, Russell AE. Lack of effect of fish oil supplementation on blood pressure in treated hypertensives. J Hypertens 1990;8:339-43.

7. Prisco D, Paniccia R, Bandinelli B, Filippini M, Francalanci I, Giusti B, Giurlani L, Gensini GF, Abbate R, Neri Serneri GG. Effect of medium-term supplementation with a moderate dose of $(n-3)$ polyunsaturated fatty acids on blood pressure in mild hypertensive patients. Thromb Res 1998;91:105-12.

8. Ruiz-Gutierrez V, Muriana FJ, Guerrero A, Cert AM, Villar J. Plasma lipids, erythrocyte membrane lipids and blood pressure of hypertensive women after ingestion of dietary oleic acid from two different sources. J Hypertens 1996;14:148390.

9. Ruiz-Gutierrez V, Muriana FJ, Guerrero A, Cert AM, Villar J. Role of dietary oleic acid from two different sources on fatty acid composition of erythrocyte membrane and blood pressure in healthy subjects. J Nutr Biochem 1997;14:1483-1490.

10. Ferrara LA, Raimondi AS, d'Episcopo L, Guida L, Dello Russo A, Marotta T. Olive oil and reduced need for antihypertensive medications. Arch Intern Med (2000) 160(6):837-42.

11. Costa FV. Non-pharmacological treatment of hypertension in women. J Hypertens 2002;20:S57-S61.

12. Masella R, Giovannini C, Vari R, Di Benedetto R, Coni E, Volpe R, Fraone N, Bucci A. Effects of dietary virgin olive oil phenols on low density lipoprotein oxidation in hyperlipidemic patients. Lipids 2001;36:1195-1202. 
13. Gimeno E, Fito M, Lamuela-Raventos RM, Castellote Al, Covas M, Farre M, de La Torre-Boronat MC, Lopez-Sabater MC.. Effect of ingestion of virgin olive oil on human low-density lipoprotein composition. Eur J Clin Nutr 2002;56:114-20.

14. Steinberg D, Parthasarathy S, Carew TE, Khoo JC, Witztum JL. Beyond cholesterol: modifications of low-density lipoprotein that increase its atherogenicity. N Engl J Med $1989 ; 320: 915-23$.

15. Berliner JA, Heinecke JW. The role of oxidized lipoproteins in atherogenesis. Free Radic Biol Med 1996;20(5):707-27.

16. De Waart F, Moser U, Kok FJ. Vitamin E supplementation in elderly lowers the oxidation rate of linoleic acid in LDL. Atherosclerosis 1997;133:255-63.

17. Balkan J, Kanblagi O, Mehmetcik G, Mutlu-Turkoglu U, Aykac-Toker G, Uysal M. Increased lipid peroxidation in serum and low-density lipoproteins associated with aging in humans. Int J Vitamin Nutr Res 2002;72:315-20.

18. Frostegard J, Wu R, Léeme C, Thulin T, Wiztum JL, De Faire U. Circulating oxidized low density lipoprotein is increased in hypertension. Clin Sci (Lond) 2003;

19. Brockes C, Buchli C, Locher R, Koch J, Vetter W. Vitamin E prevents extensive lipid peroxidation in patients with hypertension. Br J Biomed Sci 2003;60:5-8.

20. Lanzon A, Guinda A, Albi T, de la Osa C. Método rápido para la determinación de escualeno en aceites vegetales (Spanish. Rapid method for determination of squalene in vegetable oils). Grasas y Aceites 1995;46:276-78.

21. Rose G, Oaklander M. Improved procedure for the extraction of lipids from human erythrocytes. J Lipid Res 1965;6:428-31.

22. Diebolt M, Bucher B, Andriantsitohaina R. Wine polyphenols decrease blood pressure, improve NO vasodilatation and induce gene expression. Hypertension 2001;38:159-165.

23. Mensink RP, Katan MB. Effect of a diet enriched with monounsaturated or polyunsaturated fatty acids on concentrations of low-density and high-density lipoprotein cholesterol in healthy men and women. N Engl J Med 1989;321:436-41.

24. Mata P, Alvarez-Sala LA, Rubio MJ, Oya M. Effects of long-term monounsaturated vs polyunsaturated-enriched diets on lipoproteins in healthy men and women. Am J Clin Nutr 1992;55:846-50.

25. Howell TJ, MacDougall DE, Jones PJH. Phytosterols partially explain differences in cholesterol metabolism caused by corn or olive oil feeding. J Lipid Res 1998;39:892900 . 
26. Pedersen A, Baumstark MW, Marckmann P Gylling H, Sandström B. An olive oil-rich diet results in higher concentrations of LDL cholesterol and a higher number of LDL subfraction particles than rapeseed oil and sunflower oil diets. J Lipid Res 2000;41:190111.

27. Sirtori CR, Gatti E, Tremoli E, Galli C, Gianfranceschi G, Franceschini G, Colli S, Maderna P, Marangoni F, Perego P. Olive oil, corn oil, and n-3 fatty acids differently affect lipids, lipoproteins, platelets, and superoxide formation in type II hypercholesterolemia. Am J Clin Nutr 1992;25:113-22.

28. Madigan C, Ryan M, Owens D, Collins P, Tomkin GH. Dietary unsaturated fatty acids in type 2 diabetes: higher levels of postprandial lipoprotein on a linoleic acid-rich sunflower oil diet compared with an oleic acid-rich olive oil diet. Diabetes Care 2000;23(10):147277.

29. Perona JS, Huarte-Mendicoa JC, Montero E, Sánchez-Domínguez JM, Ruiz-Gutierrez V. Plasma lipid modifications in elderly people after administration of two virgin olive oils of the same variety with different triacylglycerol composition. Br J Nutr 2003;89(6):819-26. 30. Pedersen A, Baumstark MW, Marckmann P, Gylling H, Sandstrom B. An olive oil-rich diet results in higher concentrations of LDL cholesterol and a higher number of LDL subfraction particles than rapeseed oil and sunflower oil diets. J Lipid Res 2000;41(12):1901-11.

31. Reaven PD, Napoli C, Merat S, Witztumc JL.Lipoprotein modification and atherosclerosis in aging. Exp Gerontol 1999;34(4):527-37.

32. Schaefer EJ, Lichtenstein AH, Lamon-Fava S, McNamara JR, Ordovas JM. Lipoproteins, nutrition, aging, and atherosclerosis. Am J Clin Nutr 1995;61:726S-740S.

33. Napoli C, Abete P, Corso G, Malorni A, Postiglione A, Ambrosio G, Cacciatore F, Rengo F, Palumbo G. Increased low-density lipoprotein peroxidation in elderly men. Coron Artery Dis 1997;8:129-36.

34. Moline J, Bukharovich IF, Wolff MS, Phillips R. Dietary flavonoids and hypertension: is there a link? Med. Hypotheses 2000;55:306-09.

35. Giugliano D. Dietary antioxidants for cardiovascular prevention. Nutr Metab Cardiovasc Dis 2000;10:38-44.

36. Rosengren A, Stegmayr B, Johansson I, Huhtasaari F, Wilhelmsen L. Coronary risk factors, diet and vitamins as possible explanatory factors of the Swedish north-south gradient in coronary disease: a comparison between two MONICA centers. J Intern Med $1999 ; 246(6): 577-86$. 
37. Chen J, He J, Hamm L, Batuman V, Whelton PK. Serum antioxidant vitamins and blood pressure in the United States population. Hypertension 2002;40(6):810-6.

38. Singh RB, Ghosh S, Niaz MA, Singh R, Beegum R, Chibo H, Shoumin Z, Postiglione A. Dietary intake, plasma levels of antioxidant vitamins, and oxidative stress in relation to coronary artery disease in elderly subjects. Am J Cardiol 1995;76(17):1233-8.

39. Palumbo G, Avanzini F, Alli C, Roncaglioni MC, Ronchi E, Cristofari M, Capra A, Rossi S, Nosotti L, Costantini C, Cavalera C.. Effects of vitamin E on clinic and ambulatory blood pressure in treated hypertensive patients. Collaborative Group of the Primary Prevention Project (PPP)-Hypertension study. Am J Hypertens 2000;13:564-67.

40. Stephens NG, Parsons A, Schofield PM, Kelly F, Cheeseman K, Mitchinson MJ. Randomised controlled trial of vitamin $E$ in patients with coronary disease: Cambridge Heart Antioxidant Study (CHAOS) Lancet (1996) 347:781-6.

41. Kritharides L, Stocker R. The use of antioxidant supplements in coronary heart disease. Atherosclerosis 2002;164(2):211-9.

42. Moore K, Roberts LJ. Measurement of lipid peroxidation. Free Radic Res 1998;28:65971.

43. Quinones-Galvan A, Pucciarelli A, Fratta-Pasini A, Garbin U, Franzoni F, Galetta F, Natali A, Cominacini L, Ferrannini E. Effective blood pressure treatment improves LDL-cholesterol susceptibility to oxidation in patients with essential hypertension. J Intern Med 2001;250:322-26.

44. Baumgartner RN, Stauber PM, McHugh D, Koehler KM, Garry PJ. Cross-sectional age differences in body composition in persons 60+ years of age. J Gerontol A Biol Sci Med Sci 1995;50(6):M307-16.

45. Heiat A, Vaccarino V, Krumholz HM. An evidence-based assessment of federal guidelines for overweight and obesity as they apply to elderly persons. Arch Intern Med 2001;161(9):1194-203.

46. Eveleth PB, Andres R, Chumlea WC, Eiben O, Ge K, Harris T, Heymsfield SB, Launer LJ, Rosenberg IH, Solomons NW, Svanborg A, van Staveren W, Vellas B. Uses and interpretation of anthropometry in the elderly for the assessment of physical status. Report to the Nutrition Unit of the World Health Organization: the Expert Subcommittee on the Use and Interpretation of Anthropometry in the Elderly. J Nutr Health Aging 1998;2(1):5-17. 
Table 1. Fatty acid composition of the sunflower (SO) and virgin olive (VOO) oils employed in the experimental diets.

\begin{tabular}{lcc}
\hline $\begin{array}{c}\text { Fatty Acid } \\
(\mathrm{mg} / 100 \\
\mathrm{mg})\end{array}$ & so & Voo \\
\hline $16: 0$ & $6.4 \pm 0.4$ & $10.9 \pm 1.8^{2}$ \\
$16: 1, \mathrm{n}-7$ & $0.1 \pm 0.0$ & $1.1 \pm 0.3^{2}$ \\
$18: 0$ & $1.6 \pm 0.3$ & $2.4 \pm 1.3$ \\
$18: 1, \mathrm{n}-9 \mathrm{t}$ & $\mathrm{ND}$ & $0.3 \pm 0.2$ \\
$18: 1, \mathrm{n}-9$ & $25.1 \pm 1.4$ & $74.6 \pm 0.6^{2}$ \\
$18: 1, \mathrm{n}-7$ & $1.6 \pm 0.3$ & $3.5 \pm 0.1^{2}$ \\
$18: 2, \mathrm{n}-6$ & $64.5 \pm 1.2$ & $4.5 \pm 0.4^{2}$ \\
$18: 3, \mathrm{n}-3$ & $\mathrm{ND}$ & $0.6 \pm 0.2^{2}$ \\
$18: 3, \mathrm{n}-6$ & $0.9 \pm 0.1$ & $1.1 \pm 0.3$ \\
$20: 1, \mathrm{n}-9$ & $0.4 \pm 0.1$ & $0.2 \pm 0.1$ \\
$22: 0$ & $\mathrm{ND}$ & $0.8 \pm 0.1^{2}$ \\
\hline${ }^{1} \bar{x} \pm$ SD. $\mathrm{n}=3$. & & \\
${ }^{2}$ different from SO $\mathrm{p}<0.01$. & \\
${ }^{3} \mathrm{ND}:$ Not detected. & &
\end{tabular}


Table 2. Serum lipid levels $(\mathrm{mg} / \mathrm{dL}$ ) of normotensive (NT) and hypertensive (HT) elderly subjects after consuming sunflower (SO) or virgin olive oil diets (VOO).

\begin{tabular}{|c|c|c|c|c|}
\hline & NT-SO & HT-SO & NT-VOO & HT-VOO \\
\hline TC & $186.2 \pm 38.1^{\mathrm{a}}$ & $184.8 \pm 40.5^{\mathrm{a}}$ & $166.6 \pm 37.7^{b}$ & $179.2 \pm 44.2^{\mathrm{ab}}$ \\
\hline LDL-C & $113.0 \pm 35.5^{\mathrm{a}}$ & $112.0 \pm 27.9^{\mathrm{a}}$ & $99.2 \pm 32.4^{\mathrm{b}}$ & $105.7 \pm 29.3^{\mathrm{ab}}$ \\
\hline HDL- & $57.6 \pm 17.8^{\mathrm{a}}$ & $54.0 \pm$ & $48.1 \pm 14.9^{b}$ & $51.2 \pm 17.2^{\mathrm{ab}}$ \\
\hline & & $33.3^{b}$ & $96.3 \pm 43.1^{b}$ & $96.6 \pm 42.6^{\mathrm{b}}$ \\
\hline
\end{tabular}

${ }^{1} \bar{x} \pm$ SD. $\mathrm{n}=31$.

${ }^{2} \mathrm{TC}$ : total cholesterol, LDL-C: LDL-cholesterol, HDL-C: HDL-cholesterol, TG:

triacylglycerols.

${ }^{3}$ Mean values within a row sharing the same letter are not significantly different $(p>0.01)$. 
Table 3. Serum liposoluble vitamins and squalene composition $(\mu \mathrm{g} / \mathrm{mL})$ of normotensive (NT) and hypertensive (HT) elderly subjects after consuming sunflower (SO) or virgin olive oil diets (VOO).

\begin{tabular}{lcccc}
\hline & NT-SO & HT-SO & NT-VOO & HT-VOO \\
\hline$\gamma$-tocopherol & $0.4 \pm 0.1^{\mathrm{a}}$ & $0.4 \pm 0.1^{\mathrm{a}}$ & $0.4 \pm 0.1^{\mathrm{a}}$ & $0.4 \pm 0.1^{\mathrm{a}}$ \\
$\alpha$ - & $5.3 \pm 1.1^{\mathrm{a}}$ & $5.8 \pm 1.5^{\mathrm{a}}$ & $5.5 \pm 0.7^{\mathrm{a}}$ & $5.2 \pm 0.9^{\mathrm{a}}$ \\
& & & & \\
tocopherol & $1.8 \pm 0.3^{\mathrm{a}}$ & $2.1 \pm 0.5^{\mathrm{a}}$ & $2.6 \pm 0.4^{\mathrm{b}}$ & $2.6 \pm 0.5^{\mathrm{b}}$ \\
retinol & $0.28 \pm 0.09^{\mathrm{a}}$ & $0.36 \pm 0.12^{\mathrm{b}}$ & $0.33 \pm 0.15^{\mathrm{ab}}$ & $0.26 \pm 0.09^{\mathrm{a}}$ \\
squalene & \multicolumn{4}{l}{} \\
\hline${ }^{1} \overline{\boldsymbol{x}} \pm$ SD. $\mathrm{n}=31$. & \\
${ }^{2}$ Mean values within a row sharing the same letter are not significantly \\
different $(\mathrm{p}>0.01)$.
\end{tabular}


Table 4. Lipid classes composition of LDL (mg/100 mg of lipids) of normotensive (NT) and hypertensive (HT) elderly subjects after consuming sunflower (SO) or virgin olive oil diets (VOO).

\begin{tabular}{lcccc}
\hline & NT-SO & HT-SO & NT-VOO & HT-VOO \\
\hline Cholesteryl esters & $41.1 \pm 6.3^{\mathrm{a}}$ & $38.8 \pm 5.4^{\mathrm{ab}}$ & $35.7 \pm 5.6^{\mathrm{b}}$ & $40.1 \pm 4.1^{\mathrm{a}}$ \\
Free cholesterol & $12.7 \pm 1.7^{\mathrm{ab}}$ & $12.0 \pm 0.8^{\mathrm{a}}$ & $13.2 \pm 1.3^{\mathrm{b}}$ & $13.5 \pm 1.9^{\mathrm{b}}$ \\
Total cholesterol & $53.8 \pm 5.2^{\mathrm{a}}$ & $50.8 \pm 5.5^{\mathrm{b}}$ & $48.9 \pm 4.5^{\mathrm{b}}$ & $53.6 \pm 2.9^{\mathrm{a}}$ \\
Triacylglycerols & $9.3 \pm 1.7^{\mathrm{a}}$ & $12.9 \pm 1.9^{\mathrm{b}}$ & $15.2 \pm 2.6^{\mathrm{c}}$ & $11.8 \pm 2.7^{\mathrm{b}}$ \\
Diacylglycerols & $2.9 \pm 0.3^{\mathrm{a}}$ & $2.4 \pm 0.5^{\mathrm{a}}$ & $4.8 \pm 0.2^{\mathrm{b}}$ & ND \\
Monoacylglycerols & $1.8 \pm 0.2^{\mathrm{a}}$ & $1.8 \pm 0.1^{\mathrm{a}}$ & $2.6 \pm 0.8^{\mathrm{a}}$ & $2.2 \pm 0.4^{\mathrm{a}}$ \\
Phospholipids & $32.4 \pm 5.5^{\mathrm{a}}$ & $32.0 \pm 5.1^{\mathrm{a}}$ & $29.2 \pm 7.5^{\mathrm{a}}$ & $32.6 \pm 5.3^{\mathrm{a}}$ \\
\hline
\end{tabular}

${ }^{1} \bar{x} \pm$ SD. $\mathrm{n}=31$.

${ }^{2}$ Mean values within a row sharing the same letter are not significantly different $(p>0.01)$.

${ }^{3} \mathrm{ND}$ : Not detected. 
Table 5. Lipid classes composition of oxidized LDL (mg/100 mg of lipids) of normotensive (NT) and hypertensive (HT) elderly subjects after consuming sunflower (SO) or virgin olive oil diets (VOO).

\begin{tabular}{lcccc}
\hline & NT-SO & HT-SO & NT-VOO & HT-VOO \\
\hline Cholesteryl esters & $51.8 \pm 3.8^{\mathrm{a}}$ & $52.7 \pm 3.8^{\mathrm{a}}$ & $49.1 \pm 5.2^{\mathrm{a}}$ & $54.0 \pm 4.3^{\mathrm{a}}$ \\
Free cholesterol & $13.4 \pm 2.2^{\mathrm{a}}$ & $12.8 \pm 1.4^{\mathrm{ab}}$ & $13.5 \pm 2.3^{\mathrm{a}}$ & $12.0 \pm 1.8^{\mathrm{b}}$ \\
Total cholesterol & $65.2 \pm 2.9^{\mathrm{a}}$ & $65.5 \pm 2.4^{\mathrm{a}}$ & $62.6 \pm 3.1^{\mathrm{b}}$ & $66.0 \pm 3.2^{\mathrm{a}}$ \\
Triacylglycerols & $4.0 \pm 0.5^{\mathrm{a}}$ & $2.3 \pm 0.6^{\mathrm{b}}$ & $4.6 \pm 0.8^{\mathrm{a}}$ & $2.5 \pm 0.2^{\mathrm{b}}$ \\
Diacylglycerols & ND & ND & ND & ND \\
Monoacylglycerols & ND & ND & ND & ND \\
Phospholipids & $31.3 \pm 2.9^{\mathrm{a}}$ & $33.3 \pm 3.4^{\mathrm{ab}}$ & $34.2 \pm 2.6^{\mathrm{b}}$ & $33.4 \pm 4.6^{\mathrm{ab}}$ \\
\hline
\end{tabular}

${ }^{1} \bar{x} \pm$ SD. $\mathrm{n}=31$.

${ }^{2}$ Mean values within a row sharing the same letter are not significantly different $(p>0.01)$.

${ }^{3} \mathrm{ND}$ : Not detected. 

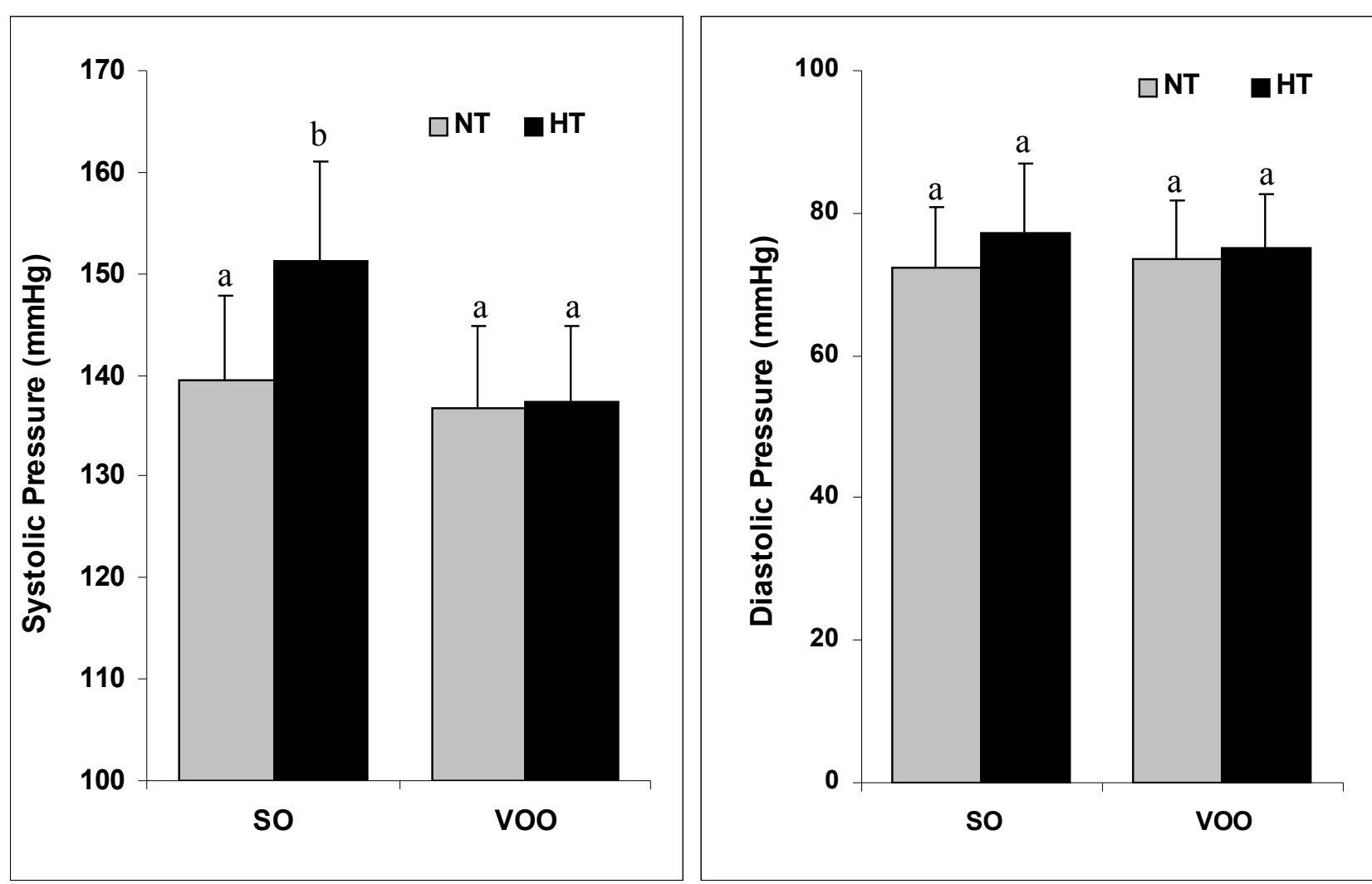


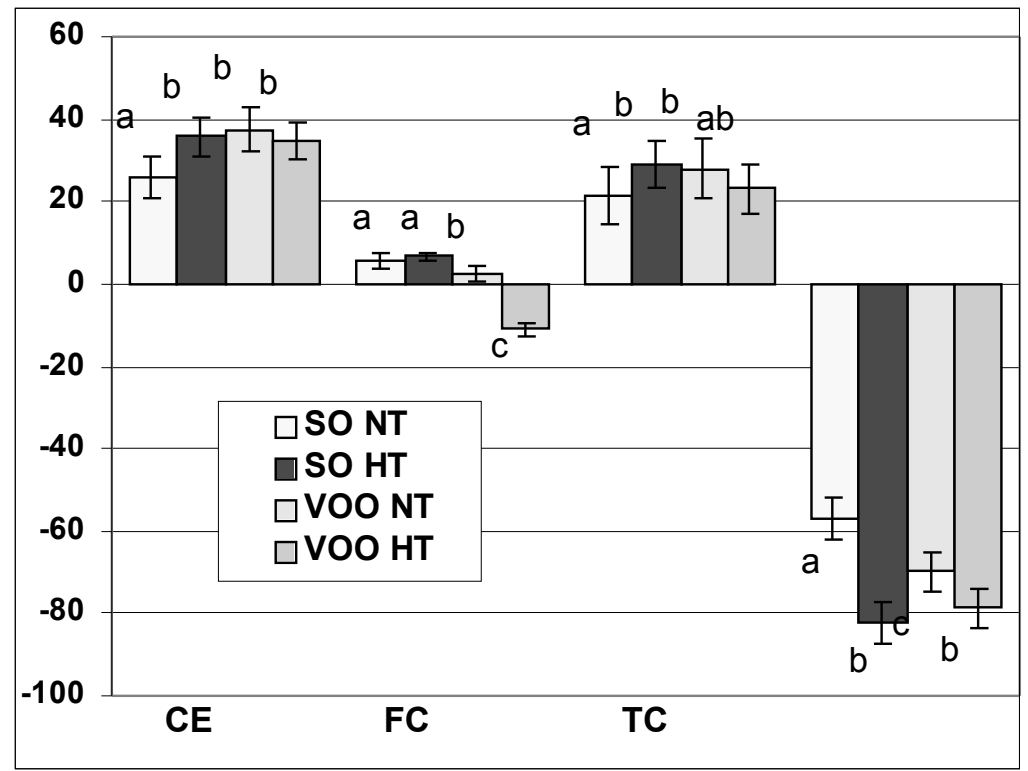


Figure 1. Systolic and diastolic pressures of normotensive (NT) and hypertensive (HT) elderly subjects after consuming sunflower (SO) or virgin olive oil diets (VOO). Mean values within a row sharing the same letter are not significantly different $(p>0.01)$.

Figure 2. Percentage of variation of cholesteryl esters (CE), free cholesterol (FC), total cholesterol (TC) and triacylglycerols (TG) in LDL due to oxidation in normotensive (NT) and hypertensive (HT) elderly subjects after consuming sunflower (SO) or virgin olive oil diets (VOO). Mean values within a row sharing the same letter are not significantly different $(p>0.01)$. 